\title{
U-W (Uranium-Tungsten)
}

\section{H. Okamoto}

The U-W phase diagram in [Massalski2] was redrawn from [1988Pan], which was based on [1950Sch], [1972Ack], and [1985Sar]. The data of [1972Ack] are preferred and weighted most heavily. Because the data points given in [1972Ack] were given only for the range $<12.5$ at. $\% \mathrm{~W}$, the phase diagram above 12.5 at. $\% \mathrm{~W}$ was drawn by speculation.

Figure 1 shows the U-W phase diagram calculated by [2008Wan]. In this calculation, the data points reported by [1986Cha] were also used, in addition to those shown in the evaluation by [1988Pan]. The (W) liquidus is higher in the diagram of [2008Wan] than that in the diagram of [1988Pan], up to $\sim 250{ }^{\circ} \mathrm{C}$ higher at $\sim 60$ at. $\% \mathrm{~W}$.

\section{References}

1950Sch: C.H. Schramm, P. Gordon, and A.R. Kaufmann, The Alloy Systems Uranium-Tungsten, Uranium-Tantalum, and Tungsten-Tantalum, Trans. AIME, 1950, 188, p 195204

1972Ack: R.J. Ackermann and E.G. Rauh, Measurements of Solubilities and Derived Thermodynamic Properties of Tungsten and Tantalum in Liquid Thorium and Uranium, High Temp. Sci., 1972, 4, p 496-505

1985Sar: A. Saroja, Y.J. Bhatt, and S.P. Garg, Determination of Thermodynamic Properties of Liquid Th-Mo, U-Mo, Th-Ta, U-Ta, Th-W, and UW Alloys from Their Diagrams, J. LessCommon Met., 1985, 114, p 291-297

1986Cha: M.S. Chandrasekharaiah, S.R. Dharwadkar, and D. Das, High-Temperature Phase Diagrams of Re-U, Ta-U, and W-U, Z. Metallkd., 1986, 77(8), p 509-514

1988Pan: S. Pandian, S.V. Nagender Naidu, and P. Rama Rao, The W-U (Tungsten-Uranium) System, J. Alloy Phase Diagrams, 1988, 4(3), p 148-153

2008Wan: J. Wang, X.J. Liu, and C.P. Wang, Thermodynamic Calculation of Phase Equilibria of the U-Ta and U-W Systems, J. Nucl. Mater., 2008, 380, p 105-110

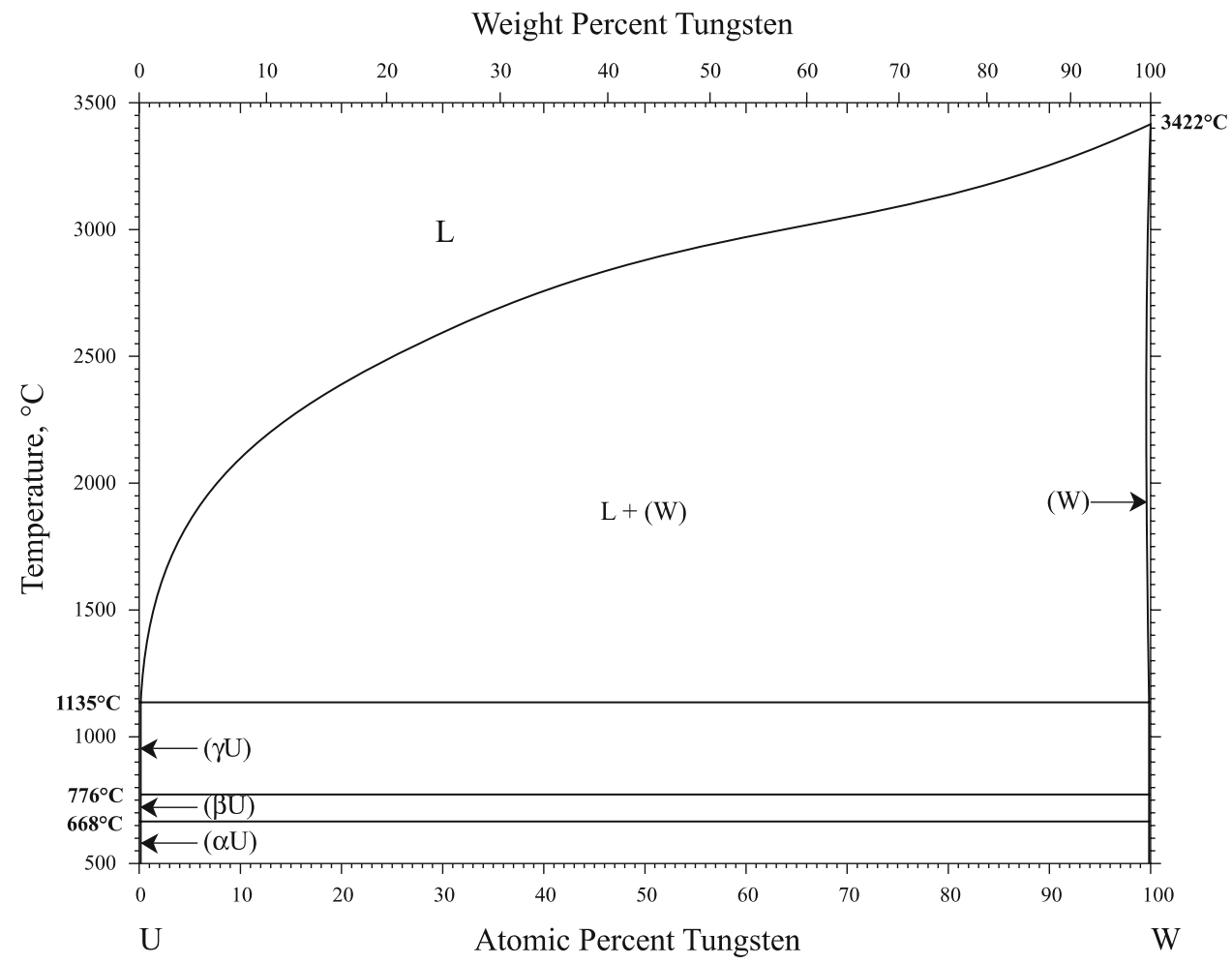

Fig. 1 U-W phase diagram 